\title{
Los servicios digitales notariales en contexto del COVID-19 en el Ecuador
}

\section{Notarial digital services in the context of COVID-19 in Ecuador}

\author{
Edwin Bolívar Prado-Calderón \\ us.edwinprado@uniandes.edu.ec \\ Universidad Regional Autónoma de los Andes, Santo Domingo \\ Ecuador \\ https://orcid.org/0000-0002-9809-1881 \\ Solange Patricia Rojas-Ochoa \\ ds.solangepro19@uniandes.edu.ec \\ Universidad Regional Autónoma de los Andes, Santo Domingo \\ Ecuador \\ https://orcid.org/0000-0002-4742-2900
}

Recepción: 15 de septiembre 2021

Revisado: 25 octubre 2021

Aprobación: 15 de noviembre 2021

Publicación: 01 de diciembre 2021 


\title{
RESUMEN
}

El objetivo general del presente estudio fue analizar desde lo jurídico los servicios digitales notariales en contexto del COVID-19 en el Ecuador. Se desarrolló en base a un enfoque científico, por la facilidad que da poder desarrollarse dentro de una observación directa en el campo, identificando el problema. Desde el paradigma cuantitativo. La metodología que se empleó es el inductivo y deductivo, permitiendo observar las particularidades y generalidades de la situación, en cuanto a los servicios notariales por falta de servicio tecnológico y en especial la Notaria del cantón Pedro Vicente Maldonado por el Covid-19. Se planteó, además el método analítico-sintético. Así mismo, el método de análisis documental y análisis de información relevante. Se aplicó una encuesta a los usuarios de las notarías. Se concluye, que es apremiante que se dé la difusión correspondiente de la seguridad de los tramites digitales para evitar que la aglomeración en las notarías.

Descriptores: Tecnología; pandemia; servicios; documentos púbicos; información consignada. (Palabras tomadas de Tesauro UNESCO).

\begin{abstract}
The general objective of this study was to analyze from the legal point of view digital notarial services in the context of COVID-19 in Ecuador. It was developed based on a scientific approach, because of the ease that it gives to be able to develop within a direct observation in the field, identifying the problem. From the quantitative paradigm. The methodology that was used is inductive and deductive, allowing to observe the particularities and generalities of the situation, in terms of notarial services due to lack of technological service and especially the Notary of the Pedro Vicente Maldonado canton for Covid-19. The analytical-synthetic method was also proposed. Likewise, the method of documentary analysis and analysis of relevant information. A survey was applied to the users of the notaries. It is concluded that it is urgent that the corresponding dissemination of the security of digital procedures be given to avoid crowding in the notaries.
\end{abstract}

Descriptors: Technology; pandemic; services; public documents; consigned information. (words takenfrom UNESCO Thesaurus). 


\section{INTRODUCCIÓN}

El presente artículo científico refiere acerca de los servicios digitales en la notaria del cantón Pedro Vicente Maldonado por el Covid 19, para ello el objetivo consiste en realizar un análisis jurídico de los recursos tecnológicos utilizados por las notarias para la transformación digital de sus servicios, y la validez juridica de los trámites realizados, como medida de prevención ante el inminente contagio por la pandemia del Covid-19.

Se debe referir que la aplicación de la tecnologia en el Ecuador en cuanto a trámites notariales han ido evolucionando, sin embargo aún tiene muchas deficiencias que deben irse solucionando para volverlas útiles y eficientes, para evitar falta de seguridad jurídica en estos trámites, sin embargo van avanzando puesto que la normativa ampara la innovación tecnológica que permite dar un servicio rápido, oportuno y eficaz. La labor notarial por mucho tiempo ha sido considerada como un trabajo de escritorio y acumulación de papel en cuanto a la realización de trámites, sin considerar la facilidad que presta la tecnología para agilitar cuanto trámite sea necesario, sin que esto implique atentar a la seguridad jurídica y con el ello evitar el tráfico de bienes y servicios.

Asi mismo, la actividad de los notarios se rige por la Ley notarial publicada en R.O. 158 del 11 de noviembre de 1966, desde entonces los sevicios notariales han venido siendo una labor lenta, de escritorio, y acumulación de papel, en cuanto a la realización de un trámite, se debe efectuar algunas solemnidades presenciales que se encuentran establecidas en la ley, provocando que los trámites sean demasiados extensos y tome varios dias.Debido a las restricciones y la situación particular que se encuentra atravesando el pais y el mundo entero por la pandemia Covid-19, se hecho inminente la necesidad de incorporar a los procesos habituales el uso de herramientas digitales aunado a los cambios drásticos en la modalidad de trabajo de todos los seres humanos, empresas e instituciones.

El servicio notarial se da a nivel mundial, siendo reconocido como una actividad sustancial que garantiza la transparencia de los acuerdos jurídicos que llevan a cabo los ciudadanos, de esa manera se espera que se efectúen estos actos con toda la 
seguridad jurídica por ser este un principio rector de una sociedad que viene siendo direccionada por el Estado, y en este caso delegado al notario, mismo que a pasos agigantados se va modernizando, y que es el deber del mismo quien sea el guardián de los derechos fundamentales al momento de desarrollar las actividades dentro del marco de la Ley.

La sociedad a nivel mundial se encuentra en una inconteniblemente travesía en cuanto a los cambios, estimulada por la universalidad de una economía, y con ello la transformación digital y la comunicación, donde la inteligencia artificial ayuda a la cadena de bloques o estructura de datos en que la información contenida se agrupa, y que gracias a la criptografía ha hecho que se gane tiempo en gestión de tramitación en todas las áreas de trabajo. La pandemia de Coronavirus o también llamado Covid19 ha hecho que se exijan cambios, abriendo la interacción profesional por medio de la tecnología, con el llamado TELETRABAJO, que es la prestación de servicios lícitos y personales, de carácter no presencial, llevada en jornadas ordinarias o especiales y fuera del lugar de trabajo, (Ministerio del Trabajo, 2020).

Esta tendencia ayudada a bajar el índice de contagios en más personas de este virus que ha cobrado miles de vidas a nivel mundial, es así que en el país de Chile han implementado la tecnología 5G, misma que es una modalidad de red inalámbrica de $8 \mathrm{~K}$ que permite descargar películas de última generación con conexión más rápida utilizada para transmitir videos en segundos, haciendo que la capacidad tecnológica sea más eficaz.

En el Ecuador por la afectación que ha traído la pandemia Mundial COVID-19, y por el mejoramiento y modernización del sistema judicial ha hecho que el Consejo de la Judicatura en la resolución 083-2020 cree el "INSTRUCTIVO OPERATIVO PARA LA IMPLEMENTACIÓN PROGRESIVA DE ACTOS, CONTRATOS Y DILIGENCIAS NOTARIALES A TRAVÉS DEL USO DE MEDIOS ELECTRÓNICOS", en el mismo que refiere su objetivo en su artículo 1 que: "El presente instructivo técnico tiene por objeto viabilizar el ámbito operativo de aplicación del "REGLAMENTO PARA LA IMPLEMENTACIÓN PROGRESIVA DE ACTOS, CONTRATOS Y DILIGENCIAS 


\section{NOTARIALES A TRAVES DEL USO DE MEDIOS ELETRÓNICOS Y REDUCCIÓN} DE TARIFAS" aprobado por el Pleno del Consejo de la Judicatura" (Judicatura, 2020) Dentro de las funciones del Notario respecto a la fe pública ante una gestión se debe atribuir por el distanciamiento, a más de la firma electrónica, la videoconferencia y medios electrónicos para la identificación de las personas a las cuales se va a prestar el servicio notarial aplicando la seguridad jurídica de manera subjetiva, es decir asegurando los derechos de las personas, normadas en la legislación ecuatoriana, ciudadanos que han expresado voluntariamente querer ejercer de manera verídica los actos notariales por medio del procedimiento de desmaterialización de los documentos para la comprobación de la originalidad del mismo, hay que recalcar que la desmaterialización se da con la respectiva autorización de las partes, ya sea por físico o electrónicamente.

La pandemia que actualmente se vive se propaga principalmente a través del contacto cercano entre personas, en menos de dos metros sin protección, sin la utilización de la mascarilla, el contagio es inesperado ya que muchos de los infectados no presentan síntoma alguno, estas infecciones se dan a través de gotitas que han expulsado personas que tienen el virus por medio de estornudos, tos, dejando esparcido en las cosas inertes durando varias horas el virus vivo, provocando esta grave enfermedad que ha dejado al mundo en un estado de desconsuelo por la pérdida de sus familiares, la pobreza entre otros resultados. (Centros para el Control y la Prevención de Enfermedades, 2020).

De lo referido en el párrafo anterior es de conocimiento general que en las notarías se necesita de la presencia de las partes, como para realizar una posesión efectiva se requiere de la firma presencial de los herederos a quienes también se los fotografía en el lugar dando el señor notario fe de lo que se está realizando y con ello surge la aglomeración del personal y del usuario corriendo el peligro de contagio.

Por otro lado, la Ley de Comercio Electrónico refiere en su artículo 13 que la Firma Electrónica son datos en forma electrónica consignados en un mensaje de datos, mismos que identifican que el titular de la firma acepta la información que va a firmar electrónicamente, así mismo en su artículo 14 de la ley referida menciona que tiene la 
misma validez y efectos jurídicos que una firma manuscrita en relación con los datos consignados en los documentos escritos y son admitidos como prueba en juicio.

Al respecto de los trámites notariales y como se ha indicado, se requiere de la presencia de los usuarios para ello se podría optar por las plataformas digitales como teams, zoom, WhatsApp, entre muchas otras que hoy en día se han creado, pues de la misma forma constituirían constancia de la presencia física de las personas ya que finalmente su contenido tiene la misma cualidad que la fotografía tomada con la presencia física.

Haciendo referencia de la resolución No. 078-2020-2020, de fecha 16 de julio de 2020, dictada por el Consejo de La Judicatura en el que resuelve priorizar el teletrabajo a nivel nacional, desarrollándose las audiencia por vía telemática/videoaudiencia, estos mecanismos no vulneran a las partes procesales por permitirles estar presente telemáticamente en las audiencias dentro de tal procedimiento el señor Juez pide identificarse a las partes, a más de ello exhibir documentación por el principio de contradicción, por tal se refleja el debido proceso, celeridad y seguridad jurídica efectiva, en razón de ello no hay pretexto que impida que las notarías pueda manejarse por alguno de estos procesos tecnológicos. (Judicatura, 2020)

Debido a lo manifestado en lineas anteriores la notaria del cantón Pedro Vicente Maldonado se ha visto en la necesidad de implementar soluciones prácticas e innovadoras para atender cada una de las necesidades a sus usuarios, a través de servicios y atención virtual, como por ejemplo las minutas redactadas por los abogados son recibidas a través del correo electrónico con su respectiva firma electrónica, pero que sin embargo aún no son muy usadas por parte de los usuarios. En este sentido el objetivo general del presente estudio es analizar desde lo jurídico los servicios digitales notariales en contexto del COVID-19 en el Ecuador. 


\section{METODOLOGÍA}

Este trabajo se ha desarrollado en base a un enfoque cientifico, por la facilidad que da poder desarrollarse dentro de una observacion directa en el campo de estudio, identificando el problema, además los métodos teórico del conocimieto de la mano del método empírico ayudan a comprender los hechos con la gestión del investigador para poder investigar y desarrollar la presente investigación. Desde el paradigma cauntitativo. La metodología a emplearse es el inductivo y deductivo, permitiendo observar las particularidades y generalidades de la situación que se encuentran padeciendo las notarias y con ellos los usuarios, en cuanto a los servicios notariales por falta de servicio tecnológico dentro de las referidas, y en especial la Notaria de el cantón Pedro Vicente Maldonado por el Covid-19. Se plantea además el método analítico-sintético por medio del cual, se descompone un todo en partes extrayendo cualidades, componentes, relaciones y más para posteriormente unir las partes analizadas y con ello descubrir características y relaciones entre los elementos (Rodríguez y Pérez, 2017).Asi mismo, el método de análisis documental permite el análisis de información de libros legales, jurisprudencia, etc como la Constitución de la República del Ecuador, Ley de Comercio Electrónico, Firmas y Mensajes de Datos. Se aplicará una encuestas a los usuarios de las notarias. 


\section{RESULTADOS}

A continuación, se presentan los resultados producto de la encueta aplicada.

1.- ¿Es seguro para usted realizar trámites notariales de manera digital?

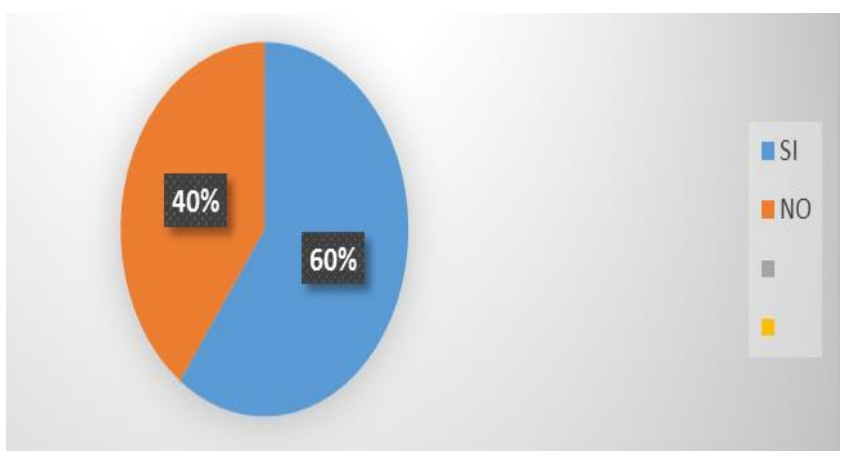

Gráfica 1. Tramites notariales

Fuente: Entrevista.

Análisis, el $40 \%$ piensa que sería seguro los tramites digitales en las notarías, y el $60 \%$ duda que sea seguro, y teme hacerlo por seguridad.

2.- ¿Cree usted qué la notaria debe tener siempre el acceso tecnológico de la información del Sistema Nacional de identificación?

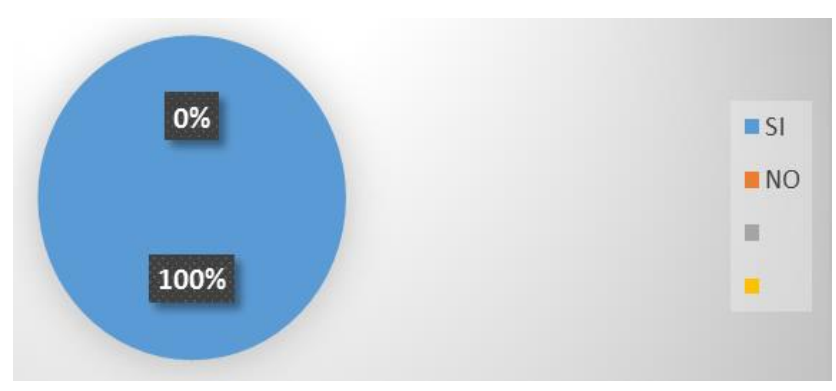

Gráfica 2. Acceso tecnológico

Fuente: Entrevista. 
Análisis, el $100 \%$ piensa que se debe tener acceso tecnológico de la información del Sistema Nacional de Identificación, para tener la seguridad de la identificación de cada requirente.

3.- ¿Conoce qué es la desmaterialización electrónica de documentos?

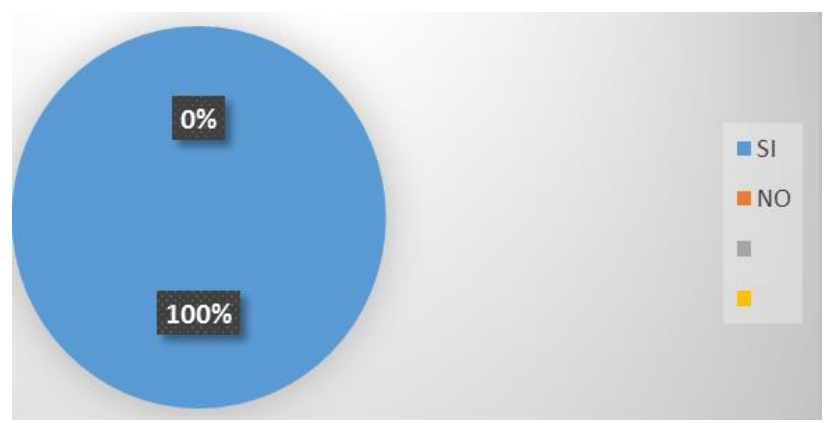

Gráfica 3. Desmaterialización

Fuente: Entrevista.

Análisis, el 100\% conoce sobre la desmaterialización de los documentos.

4.- ¿Usted hace uso de la firma electrónica para agilizar los trámites?

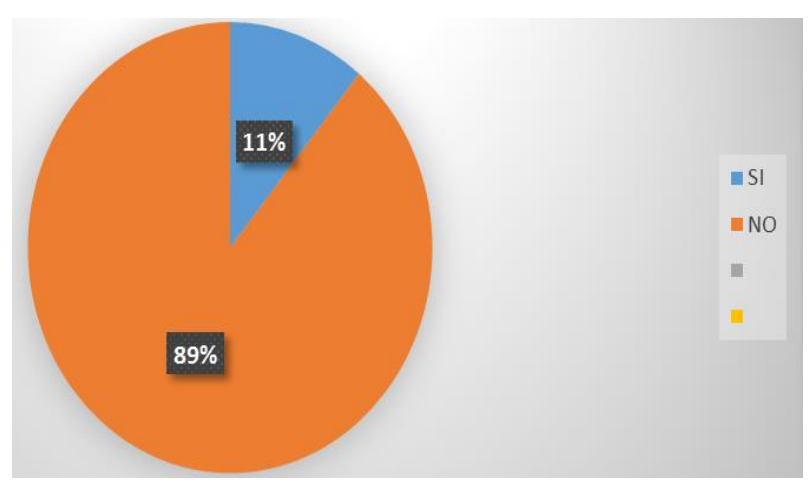

Gráfica 3. Uso de firma electrónica.

Fuente: Entrevista. 
Análisis, el $11 \%$ hace uso de la firma electrónica, y el $89 \%$ no lo usa por temor o desconocimiento.

5.- ¿Ha requerido el servicio notarial en tiempo de pandemia?

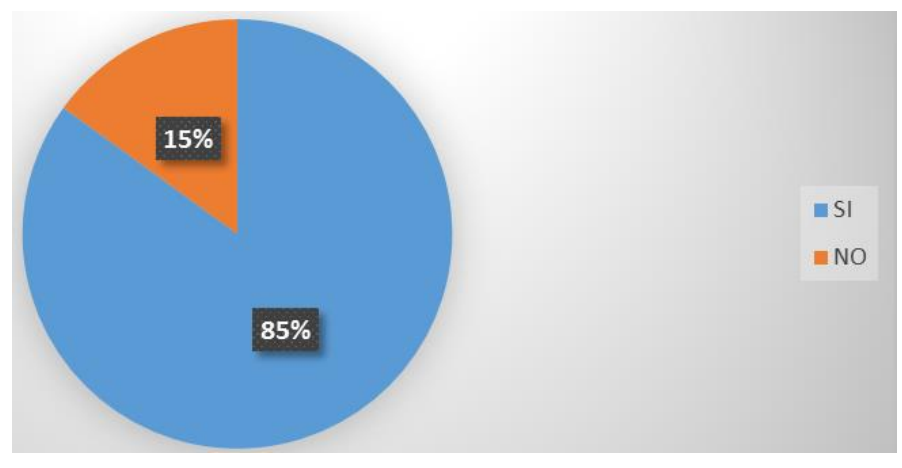

Gráfica 3. Servicio de notaria en pandemia.

Fuente: Entrevista.

Análisis: El 15\% no ha requerido del servicio, mientras que el $85 \%$ si puesto que es los tramites notariales son requeridos para todo tramite en cualquier entidad.

\section{DISCUSIÓN}

Los resultados arrojados en el presente artículo científico, se generan desde la importancia de manejar la tecnología dentro de las notarías a nivel nacional y en especial en el canto Pedro Vicente Maldonado, lugar donde aún falta impulsar las modalidades de tecnología de manera eficiente y eficaz. Así mismo, el análisis documental que se ha observado en la normativa ecuatoriana, se puede manifestar que si bien es cierto la Ley ampara la tecnología en las notarías hace falta una normativa legal que regule las nuevas tecnologías implementadas ofreciendo el mejor manejo documental de manera digital, se insiste en la necesidad de manejar los servicios notariales de manera digital como lo efectúan en el país de Colombia, donde por una única ves asisten presencialmente para poder ingresar sus datos y obtener claves que permitan luego dar el servicio por medio de la página virtual de la notaria. En el Ecuador el consejo de la Judicatura debe implementar un sistema informático 
que permita almacenar los archivos que se van digitalizando en todas las notarías del país, facilitando encontrar archivos.

En la encuesta a los usuarios del cantón Pedro Vicente Maldonado, donde los referidos en su mayoría creen que los tramites digitales serian una buena opción, pero como trabajadora de la notaria se ha visualizado que lo refieren de manera dudosa, por el desconocimiento de la seguridad de la modalidad. En cuanto a que se debe tener acceso tecnológico al sistema de tener el acceso tecnológico de la información del Sistema Nacional de Identificación, todos estuvieron de acuerdo, ya que esto asegura que se haga todo legalmente.

\section{CONCLUSIONES}

Según la normativa del Ecuador está estipulada la realización de trámites notariales con la utilización de la tecnología, en ese sentido lo refiere la Ley Notarial y la Ley de Comercio Electrónico, mediante la incorporación de firmas electrónicas y mensajes de datos como herramientas que puede ser aplicadas para realizar trámites a través de plataformas electrónicas, evidenciando que el manejo tecnológico ha avanzado pero que en el cantón Pedro Vicente Maldonado existen dudas y miedos por parte de los usuarios, debido a que muy poco utilizan la firma electrónica, y por ende las plataformas digitales, tano por desconfianza como por la falta de conocimiento.

Los resultados evidenciaron que los trámites por medio de la tecnología en la actualidad es inevitable y son necesarios, puesto a que ahorra tiempo y dinero, ha quedado atrás la acumulación de papel el archivo digital ha sido el primer paso en dirección a un mundo digitalizado, no obstante se ha evidenciado que hay falta de capacitación hacia la ciudadanía para que pueda optar por el uso de medios electrónicos y con el ello se obtenga provecho en beneficio de los usuarios y en definitiva progreso para el país.

El uso del sistema notarial en tiempos de pandemia con el uso de medios tecnológicos evita el desplazamiento hacia el lugar de tramitación, siempre y cuando existan los cuatro aspectos que generen la seguridad jurídica en los trámites como lo son la 
identidad, integridad, confidencialidad y el no repudio. Por tal es apremiante que se dé la difusión correspondiente de la seguridad de los tramites digitales para evitar que por la aglomeración en las notarías más gente se contagie del virus de covid-19, y con ello se atente a los derechos de las personas constitucionalmente establecidos.

\section{FINANCIAMIENTO}

No monetario.

\section{AGRADECIMIENTO}

A la Universidad Regional Autónoma de los Andes, Santo Domingo, por motivar el desarrollo de la Investigación.

\section{REFERENCIAS CONSULTADAS}

Asamblea Nacional Constituyente de la República del Ecuador, (2008). Constitución de la República del Ecuador. [Constitution of the Republic of Ecuador].Montecristi. Registro Oficial 449 de 20-oct-2008. Recuperado de https://n9.cl/sia

Centros para el Control y la Prevención de Enfermedades. (2020) Formas en las que se propaga el COVID-19. [ Ways in which COVID-19 spreads]. Recuperado de: https://n9.cl/g54zu

Congreso Nacional (2020). Ley de Comercio Electrónico, Firmas Electrónicas y Mensajes de Datos. (Ley No. 2002-67). [Law on Electronic Commerce, Electronic Signatures and Data Messages]. Recuperado de: https://n9.cl/icjz

Consejo de la Judicatura. (16 de mayo de 2016). Resolución 078-2016.[ Resolution 078-2016]. Recuperado de: https://n9.cl/sldjlx

Consejo de la Judicatura. (09 de enero de 2021). Protocolo y regulaiones que permitan a las notarías y notarios utilizar otras plataformas y herramientas electrónicas.[ Protocol and regulations that allow notaries and notaries to use other platforms and electronic tools]. Recuperado de: https://n9.cl/axrh2

Consejo de la judicatura (2020). Resolución 078-2020 el Pleno del Consejo de la Judicatura. [ Resolution 078-2020 the Plenary of the Council of the Judiciary]. Recuperado de: https://n9.cl//4n1f 
Judicatura, C. d. (28 de julio de 2020). Resolución 083-2020. Aprobar el Instructivo operativo para la implementación progresiva de actos, contratos y diligencias notariales a trave's del usi de medios electronicos.[ Resolution 083-2020. Approve the Operational Instructions for the progressive implementation of acts, contracts and notarial proceedings through the use of electronic media]. Quito, Pichincha, Ecuador.

Judicatura, P. d. (16 de julio de 2020). Resolución 078-2020.[Resolution 078-2020]. Recuperado de: https://n9.cl//4n1f

Ministerio del Trabajo (2020). Teletrabajo. [Telecommuting]. Recuperado de: https://n9.cl/bsn80

Rodríguez Jiménez, A., y Pérez Jacinto, A. (2017). Métodos científicos de indagación y de construcción del conocimiento. [Scientific methods of inquiry and construction of knowledge]. Revista EAN (82), 179-200. https://doi.org/10.21158/01208160.n82.2017.1647 